\title{
Denatured proteins as a novel template for the synthesis of well-defined, ultra-stable and water-soluble metal nanostructures for catalytic applications
}

\author{
Chaojian Chen ${ }^{1,2^{*}}$, David Yuen Wah $\mathrm{Ng}^{1}$ and Tanja Weil ${ }^{1,2^{*}}$
}

\begin{abstract}
The templated synthesis of noble metal nanoparticles using biomass, such as proteins and polysaccharides, has generated great interest in recent years. In this work, we report on denatured proteins as a novel template for the preparation of water-soluble metal nanoparticles with excellent stability even after high speed centrifugation or storage at room temperature for one year. Different noble metal nanoparticles including spherical gold and platinum nanoparticles as well as gold nanoflowers are obtained using sodium borohydride or ascorbic acid as the reducing agent. The particle size can be controlled by the concentration of the template. These metal nanoparticles are further used as catalysts for the hydrogenation reaction of $p$-nitrophenol to $p$-aminophenol. Especially, spherical gold nanoparticles with an average size of $2 \mathrm{~nm}$ show remarkable catalytic performance with a rate constant of $1.026 \times 10^{-2} \mathrm{Ls}^{-1} \mathrm{mg}^{-1}$. These metal nanoparticles with tunable size and shape have great potential for various applications such as catalysis, energy, sensing, and biomedicine.
\end{abstract}

Keywords: Unfolded proteins, Gold nanoparticles, Gold nanoflowers, Platinum nanoparticles, Biotemplated synthesis, Catalysis

\section{Introduction}

Due to their high surface-to-volume ratios and quantum size effects, noble metal nanoparticles exhibit distinct optical, thermal, and chemical properties from their bulk counterparts $[1,2]$. These nanoparticles with controlled sizes and shapes have received tremendous attention in a myriad of areas including catalysis, energy, optics, sensing, biomedicine, and leather industry [3-7]. For example, gold nanoparticles (AuNPs) have shown remarkable catalytic activities for many organic transformations such as addition to carbon-carbon bonds, oxidation of carbon monoxide and alcohols, selective hydrogenations, and carbon-carbon coupling reactions [8-10]. However, metal

\footnotetext{
* Correspondence: chenc@mpip-mainz.mpg.de; weil@mpip-mainz.mpg.de ${ }^{1}$ Max Planck Institute for Polymer Research, Ackermannweg 10, 55128 Mainz, Germany

Full list of author information is available at the end of the article
}

nanoparticles aggregate easily which greatly hinders their usage in catalysis, biomedicine, and many other fields. To solve this problem, a variety of substances including thiolcontaining surfactants and polymers have been developed for surface functionalization of metal nanoparticles with long-term stability and dispersity [11-14]. It should be noted that this strategy may involve tedious synthetic and purification steps, harsh reaction conditions, and the use of toxic organic solvents $[15,16]$.

Recently, the environmentally friendly synthesis and stabilization of metal nanoparticles using biopolymers have become a trend [15-19]. For instance, chitosan [20-22], cellulose [23], gelatin [24], bovine serum albumin [25, 26], and collagen that can be extracted from leather products [27], have been reported as templates for the synthesis of gold nanoparticles at room temperature. In the past decade, our group has developed a facile synthesis route to unfold 
native proteins including human serum albumin (HSA) and lysozyme to well-defined linear biopolymers [28, 29]. Such protein-derived polymers offer many fascinating characteristics such as biocompatibility, biodegradability, predetermined length, narrow size distribution, and a defined number of functional groups at distinct positions along the polypeptide backbone [30]. In addition, the conjugated PEG chains can reduce protein binding and prolong circulation time in the blood stream. Therefore, these proteinderived polymers are particularly attractive for biomedical applications and as templates for preparation of precision nanomaterials. For example, multifunctional nanoparticles have been constructed by coating these protein-derived biopolymers to the surface of quantum dots, gold nanostructures, and nanodiamonds [28, 31-33]. The resulting nanohybrids which display excellent stability and biocompatibility, have been successfully used in gene transfection, cell imaging, and cancer therapy [31, 32, 34].

In this work, we report on unfolded protein backbones that possess a large number of amino groups able to bind metal ions and using them to act as novel templates for the preparation of noble metal nanoparticles with controlled sizes and shapes. Two reducing agents, ascorbic acid and sodium borohydride, are used to control the shape, and the template concentration is discovered to control the size of nanoparticles. Anisotropic gold nanoflowers (AuNFs) as well as ultrasmall spherical AuNPs and platinum nanoparticles (PtNPs) with high water solubility, excellent stability and good biocompatibility have been obtained. The template is derived from natural polymers, and the whole process is conducted in aqueous solution at room temperature. Therefore, the route can be regarded as an environmentally friendly procedure. More significantly, the well-defined nanoparticles demonstrate excellent catalytic performances for the hydrogenation reaction of $p$-nitrophenol to $p$-aminophenol. Collectively, these metal nanoparticles prepared using the novel protein-derived template may find great potential in surface-enhanced Raman spectroscopy, photothermal therapy, catalysis, biomedicine, textiles, and functional coatings for leather products.

\section{Experimental section}

\subsection{Materials}

Human serum albumin (HSA, 96\%), tris(2-carboxyethyl) phosphine hydrochloride (TCEP, $\geq 98 \%), \quad O-[(N$-succi nimidyl)succinyl-aminoethyl]-O'-methylpolyethylene glycol (NHS-PEG, $\left.M_{n} \sim 2000\right), p$-nitrophenol (99\%), $N$-(2-aminoethyl) maleimide trifluoroacetate salt (MI- $\left.\mathrm{NH}_{2}, 95 \%\right)$, $N$-(3-dimethylaminopropyl)- $N$ '-ethylcarbodiimide hydrochloride (EDC. $\mathrm{HCl}, \geq 98 \%$ ), and L-ascorbic acid ( $\geq 99 \%)$ were purchased from Sigma-Aldrich and used without further treatment. Gold (III) chloride trihydrate $\left(\mathrm{HAuCl}_{4} \cdot 3 \mathrm{H}_{2} \mathrm{O}, \geq 99.5 \%\right)$ was obtained from Carl Roth.
Ethylendiamine (>99\%), urea (99.5\%), hydrogen hexachloroplatinate (IV) hydrate $\left(\mathrm{H}_{2} \mathrm{PtCl}_{6} \cdot \mathrm{xH}_{2} \mathrm{O}, 99.9 \%, 39 \%\right.$ $\mathrm{Pt}$ ), and ethylenediaminetetraacetic acid (EDTA, 98\%) were purchased from Acros Organics and used as received. Sodium borohydride $\left(\mathrm{NaBH}_{4},>95 \%\right)$ was obtained from Fisher Chemical. All other solvents and salts were obtained from commercial suppliers and used as received.

\subsection{Synthesis of cationic HSA (cHSA) [32, 34]}

HSA (150 mg, $2.26 \mu \mathrm{mol}$ ) was dissolved in $15 \mathrm{~mL}$ of degassed ethylenediamine solution $(2.5 \mathrm{M})$, and the $\mathrm{pH}$ was tuned to 4.75 by using $\mathrm{HCl}$. After adding EDC. $\mathrm{HCl}$ $(4 \mathrm{mmol}, 766 \mathrm{mg})$ and stirring for two hours at room temperature, acetate buffer $(1 \mathrm{~mL}, 4 \mathrm{M}, \mathrm{pH} 4.75)$ was added to terminate the reaction. The obtained reaction solution was purified twice with acetate buffer $(100 \mathrm{mM}$, $\mathrm{pH} 4.75)$ and thrice with deionized water by ultracentrifugation using a Vivaspin 20 concentrator (MWCO 30 $\mathrm{kDa}$ ). The resulting solution was lyophilized to afford the product as a white fluffy solid (160 mg, yield: $98 \%$, MALDI-ToF MS: $72.3 \mathrm{kDa}$ ).

\subsection{Preparation of PEGylated cHSA (PEG-cHSA) $[32,34]$}

cHSA (101 mg, $1.40 \mu \mathrm{mol})$ was firstly dissolved in degassed phosphate buffer ( $30 \mathrm{~mL}, 50 \mathrm{mM}, \mathrm{pH}$ 8.0). NHSPEG (159.6 mg, $79.8 \mu \mathrm{mol}$ ) was dissolved in $0.6 \mathrm{~mL}$ of DMSO and then added into the cHSA solution. After stirring at room temperature for four hours, the reaction solution was purified five times with deionized water by ultracentrifugation using a Vivaspin 20 concentrator (MWCO $30 \mathrm{kDa}$ ). The resulting solution was lyophilized to obtain the product as a white fluffy solid $(206 \mathrm{mg}$, yield: $90 \%)$. The MALDI-ToF MS indicates a molecular weight of $164.3 \mathrm{kDa}$ which means on average 46 PEG chains were conjugated into each cHSA backbone.

\subsection{Synthesis of denatured PEG-cHSA (PEG-dcHSA) [32, 34]}

Urea-phosphate buffer with $50 \mathrm{mM}$ phosphate buffer, $5 \mathrm{M}$ urea and $2 \mathrm{mM}$ EDTA (urea-PB, $\mathrm{pH} 7.4$ ) was firstly prepared by dissolving urea $(150.15 \mathrm{~g}, 2.5 \mathrm{~mol})$, EDTA (292.24 mg, $1 \mathrm{mmol}), \mathrm{Na}_{2} \mathrm{HPO}_{4} \cdot 7 \mathrm{H}_{2} \mathrm{O}(5.4276 \mathrm{~g}, 25 \mathrm{mmol})$ and $\mathrm{NaH}_{2} \mathrm{PO}_{4}(0.5699 \mathrm{~g}, 25 \mathrm{mmol})$ in $0.5 \mathrm{~L}$ of Milli-Q water. Then, $80 \mathrm{~mL}$ of urea-PB was added in a $250 \mathrm{~mL}$ flask and degassed via bubbling by argon for five minutes. Followed PEG-cHSA (100 mg, $0.61 \mu \mathrm{mol})$ was dissolved and further stirred for $15 \mathrm{~min}$. TCEP $(9.0 \mathrm{mg}, 31 \mu \mathrm{mol})$ was added and stirred for 30 min under argon flow. Lastly, MI- $\mathrm{NH}_{2}(46 \mathrm{mg}, 181 \mu \mathrm{mol})$ was added and stirred overnight under argon protection. The obtained reaction solution was purified three times with urea-PB and five times with deionized water by ultracentrifugation using a Vivaspin 20 concentrator (MWCO $30 \mathrm{kDa}$ ). The resulting solution was lyophilized to afford the product as a white fluffy solid (99 mg, yield: 96\%, MALDI-ToF MS: $168.5 \mathrm{kDa}$ ). 


\subsection{Synthesis of AuNPs using $\mathrm{NaBH}_{4}$ as the reducing agent}

The molar ratio of $\mathrm{HAuCl}_{4}$ to amino groups in PEGdcHSA for the synthesis of AuNPs was tuned from 3:0 to 3:3. Take the molar ratio of 3:3 as an example, $1.5 \mathrm{mg}$ of PEG-dcHSA was dissolved in $4.4 \mathrm{~mL}$ of Milli-Q water and then $0.5 \mathrm{~mL}$ of $\mathrm{HAuCl}_{4}$ aqueous solution $(2 \mathrm{mM})$ was added and stirred for one hour. Afterwards, $0.1 \mathrm{~mL}$ of freshly prepared $\mathrm{NaBH}_{4}$ solution $(100 \mathrm{mM})$ was added dropwise under vigorous stirring. The color of the solution changed immediately to yellow. After stirring for one more hour, the solution was measured by UV-vis spectrometry. The product was purified five times with deionized water by ultracentrifugation using a Vivaspin 6 concentrator (MWCO $30 \mathrm{kDa})$.

\subsection{Synthesis of AuNFs using ascorbic acid as the reducing agent}

For the preparation of AuNFs, the reducing agent solution $(100 \mathrm{mM})$ was obtained by dissolving L-ascorbic acid $(176.1 \mathrm{mg})$ in $10 \mathrm{~mL}$ of degassed Milli-Q water. Most procedures and conditions are the same with those used for the synthesis of AuNPs in section 2.5, and the only difference is that L-ascorbic acid was used to replace $\mathrm{NaBH}_{4}$ as the reducing agent.

\subsection{Synthesis of PtNPs using $\mathrm{NaBH}_{4}$ as the reducing agent} The procedures for the synthesis of PtNPs are similar to those used for preparing AuNPs. $\mathrm{H}_{2} \mathrm{PtCl}_{6}$ solution (2 $\mathrm{mM}$ ) was obtained by dissolving $10 \mathrm{mg} \mathrm{H}_{2} \mathrm{PtCl}_{6} \cdot \mathrm{xH}_{2} \mathrm{O}$ $(39 \% \mathrm{Pt})$ in $10 \mathrm{~mL}$ Milli-Q water. The molar ratios of $\mathrm{H}_{2} \mathrm{PtCl}_{6}$ to amino groups in PEG-dcHSA were 3:2 and 3: 0 . The solutions were stirred overnight before use.

\subsection{Catalytic reduction of $p$-nitrophenol to $p$-aminophenol} To a $20 \mathrm{~mL}$ glass bottle, $3 \mathrm{~mL}$ of freshly prepare $p$-nitrophenol aqueous solution $(1 \mathrm{mM}, \mathrm{pH}=12)$ and $15 \mathrm{~mL}$ of $\mathrm{NaBH}_{4}$ aqueous solution $(50 \mathrm{mM}$ dissolved in Milli-Q water) were firstly added and gently shaken. Followed $1.2 \mathrm{~mL}$ of the mixed solution of $\mathrm{NaBH}_{4}$ and $p$-nitrophenol was added into a vial and determined amounts of metal nanocatalysts were added and the reaction was monitored by UV-vis spectrometer. The absorbance at $400 \mathrm{~nm}$ is subtracted from that at $500 \mathrm{~nm}$ to correct for background absorption and then used to calculate the conversion and apparent rate constant $\left(k_{\text {app }}\right)$. The conversion $(C)$ is calculated using the following equation:

$$
C=\frac{A_{0}-A_{t}}{A_{0}} \times 100 \%
$$

where $A_{o}$ and $A_{t}$ are the absorbance at time 0 and the The apparent rate constant $\left(k_{\text {app }}\right)$ is determined as the slope of $\ln \left(A_{O} / A_{t}\right)$ at $400 \mathrm{~nm}$ against the reaction time.

\subsection{Characterization}

UV-vis absorbance spectra were collected using a TECAN (Spark 20 M) microplate reader. The samples were added in a Greiner 96 flat transparent plate. The wavelength range was set from 250 to $800 \mathrm{~nm}$. Matrixassisted laser desorption/ionization time-of-flight (MALDI-ToF) mass spectrometry was performed on Bruker rapifleX spectrometer. Saturated solution of sinapinic acid dissolved in a 1:1 water/acetonitrile with $0.2 \%$ trifluoroacetic acid was used as the matrix solution and different concentrations of samples were measured. Transmission electron microscopy (TEM) samples were prepared by adding $4 \mu \mathrm{L}$ of the metal nanoparticle solution onto a carbon-coated copper grid. After drying in air for $10 \mathrm{~min}$, the remaining solution was removed by blotting with a filter paper. The measurement was conducted on a JEOL JEM-1400 TEM operating at an accelerating voltage of $120 \mathrm{kV}$. ImageJ software was used for the analysis of particle size.

\section{Results and discussion}

3.1 Unfolding native proteins to well-defined biopolymers The synthesis of protein-derived biopolymer PEGdcHSA and its application as a novel template for the preparation of metal nanoparticles are schematically illustrated in Fig. 1a. Firstly, the native protein HSA was cationized by converting carboxyl groups on the surface to primary amino groups. In order to prevent protein aggregation during the following denaturation step, short polyethylene glycol (PEG) chains with an average molecular weight of $2000 \mathrm{~g} \mathrm{~mol}^{-1}$ were introduced. These biocompatible PEG chains also afford PEG-cHSA with improved solubility and stability due to the steric effect between different chains. Subsequently, PEG-cHSA was unfolded in urea-phosphate buffer in the presence of TCEP as a reducing agent. In this step, urea could break the hydrogen bonds and other supramolecular forces. The 17 disulfide bridges in the 3D structure of HSA were also destroyed by TCEP, and the generated thiol groups were capped by MI-NH${ }_{2}$. Therefore, the number of primary amino groups was further increased, which resulted in better solubility and metal ion binding ability of PEG-dcHSA. MALDI-ToF mass spectra in Fig. 1b show the increase of molecular mass in each step, confirming the successful synthesis of the PEGylated linear polypeptide PEG-dcHSA.

\subsection{Ultrasmall AuNPs prepared using $\mathrm{NaBH}_{4}$ as the reducing agent}

The protein-derived linear biopolymer PEG-dcHSA which possesses abundant primary amino groups that can bind various metal-containing anions was used as a template for the in situ synthesis of different metal nanoparticles. First, we investigated the templated 


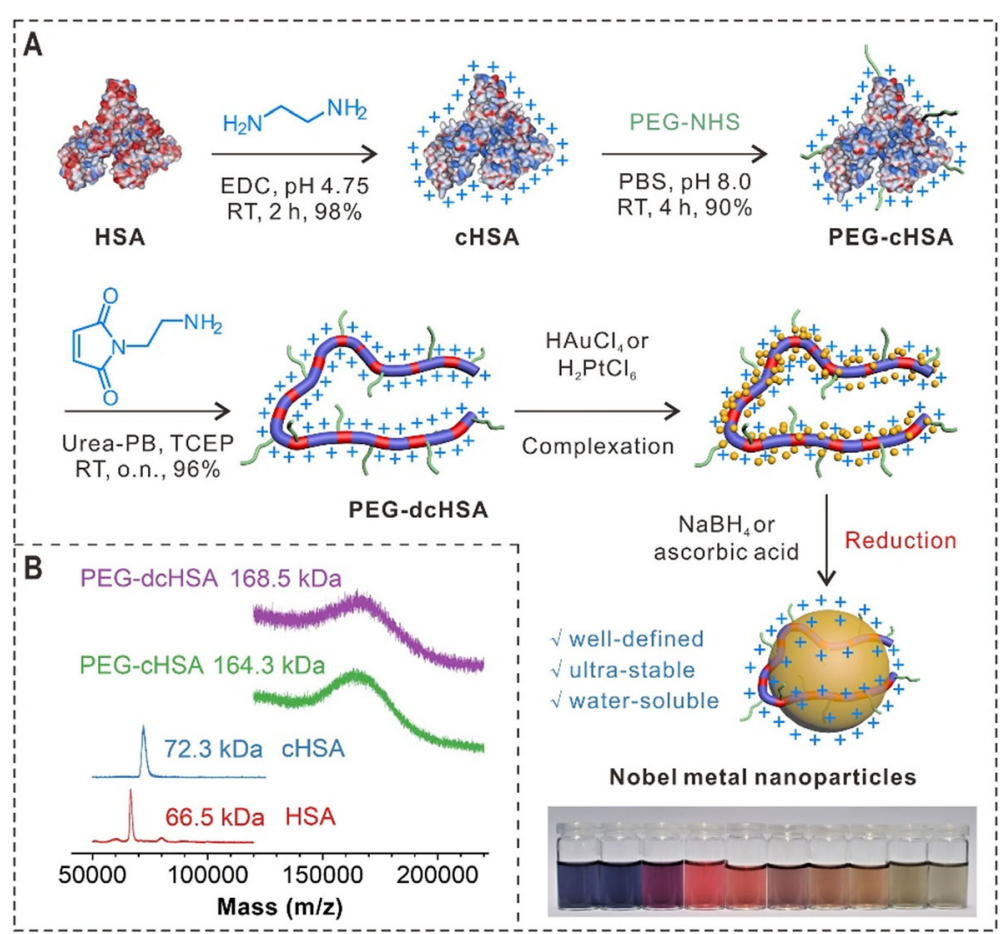

Fig. 1 a Schematic illustration for the preparation of denatured protein PEG-dcHSA and its application as a template for the synthesis of metal nanoparticles. $\mathbf{b}$ MALDI-ToF mass spectra showing the successful synthesis of PEG-dcHSA

synthesis of AuNPs using $\mathrm{NaBH}_{4}$ as the reducing agent. In a typical procedure, PEG-dcHSA was dissolved in Milli-Q water and then mixed with $\mathrm{HAuCl}_{4}$ aqueous solution for one hour. Subsequently, freshly prepared $\mathrm{NaBH}_{4}$ solution was added dropwise under vigorous stirring. The reaction solution changed immediately to yellow, pink or red depending on the added amount of PEG-dcHSA. After stirring for one more hour, the product was purified by five ultracentrifugation cycles with deionized water using a Vivaspin 6 concentrator (MWCO $30 \mathrm{kDa}$ ). As PEG-dcHSA is a precision polymer derived from HSA, the average number of primary amino groups in PEG-dcHSA was calculated as 147 (see supplementary information for more details). The molar ratio of chloroauric acid $\left(\mathrm{HAuCl}_{4}\right)$ to amino groups in PEG-dcHSA was tuned from 3:0 to 3:3 by fixing the amount of $\mathrm{HAuCl}_{4}$ and gradually increasing the amount of the denatured proteins. The details for the synthesis of AuNPs with different $\mathrm{HAuCl}_{4} /-\mathrm{NH}_{2}$ molar ratios are summarized in Table 1.

The reaction was very fast as indicated by the swift change of the solution color after adding the reducing agent. As displayed on the top panel of Fig. 2a, the color gradually shifts from red to light brown with the increased amount of denatured proteins. The UV-vis absorbance spectrum in Fig. 2b shows a characteristic peak at $512 \mathrm{~nm}$ for the sample without adding the template $\left(\mathrm{HAuCl}_{4} /-\mathrm{NH}_{2}\right.$ molar ratio $\left.=3: 0\right)$. In contrast, the peaks of the other three samples are weaker and a blue shift is observed when the amount of PEG-dcHSA is increased, indicating reduction of size for these AuNPs [35, 36]. TEM was further used to directly observe the morphology of AuNPs and the results are displayed in Fig. 2c$k$. We can see that AuNPs prepared under four different $\mathrm{HAuCl} /--\mathrm{NH}_{2}$ molar ratios all display good dispersity, narrow distributions, and spherical shapes. The AuNPs prepared with a $\mathrm{HAuCl}_{4} /-\mathrm{NH}_{2}$ molar ratio of 3:0 has an average diameter of $6.4 \pm 2.2 \mathrm{~nm}$. Ultrasmall AuNPs with the size of $2 \sim 5 \mathrm{~nm}$ were obtained when the denatured protein template was added to the reaction solutions. Increasing the added amount of PEG-dcHSA made the particle size smaller, which is consistent with the UV-vis spectra. Therefore, we can conclude that the proteinderived biopolymer can be used as an ideal template for the preparation of ultrasmall AuNPs together with the use of $\mathrm{NaBH}_{4}$ as the reducing agent.

Table 1 Conditions for the synthesis of ultrasmall AuNPs using $\mathrm{NaBH}_{4}$ as the reducing agent

\begin{tabular}{lllll}
\hline $\begin{array}{l}\mathrm{HAuCl}_{4} /-\mathrm{NH}_{2} \\
\text { molar ratio }\end{array}$ & $\begin{array}{l}\mathrm{HAuCl}_{4} \\
(2 \mathrm{mM})\end{array}$ & PEG-dcHSA & $\mathrm{H}_{2} \mathrm{O}$ & $\begin{array}{l}\mathrm{NaBH}_{4} \\
(100 \mathrm{mM})\end{array}$ \\
\hline $3: 0$ & $0.5 \mathrm{~mL}$ & $0 \mathrm{mg}$ & $4.4 \mathrm{~mL}$ & $0.1 \mathrm{~mL}$ \\
$3: 1$ & $0.5 \mathrm{~mL}$ & $0.5 \mathrm{mg}$ & $4.4 \mathrm{~mL}$ & $0.1 \mathrm{~mL}$ \\
$3: 2$ & $0.5 \mathrm{~mL}$ & $1.0 \mathrm{mg}$ & $4.4 \mathrm{~mL}$ & $0.1 \mathrm{~mL}$ \\
$3: 3$ & $0.5 \mathrm{~mL}$ & $1.5 \mathrm{mg}$ & $4.4 \mathrm{~mL}$ & $0.1 \mathrm{~mL}$ \\
\hline
\end{tabular}




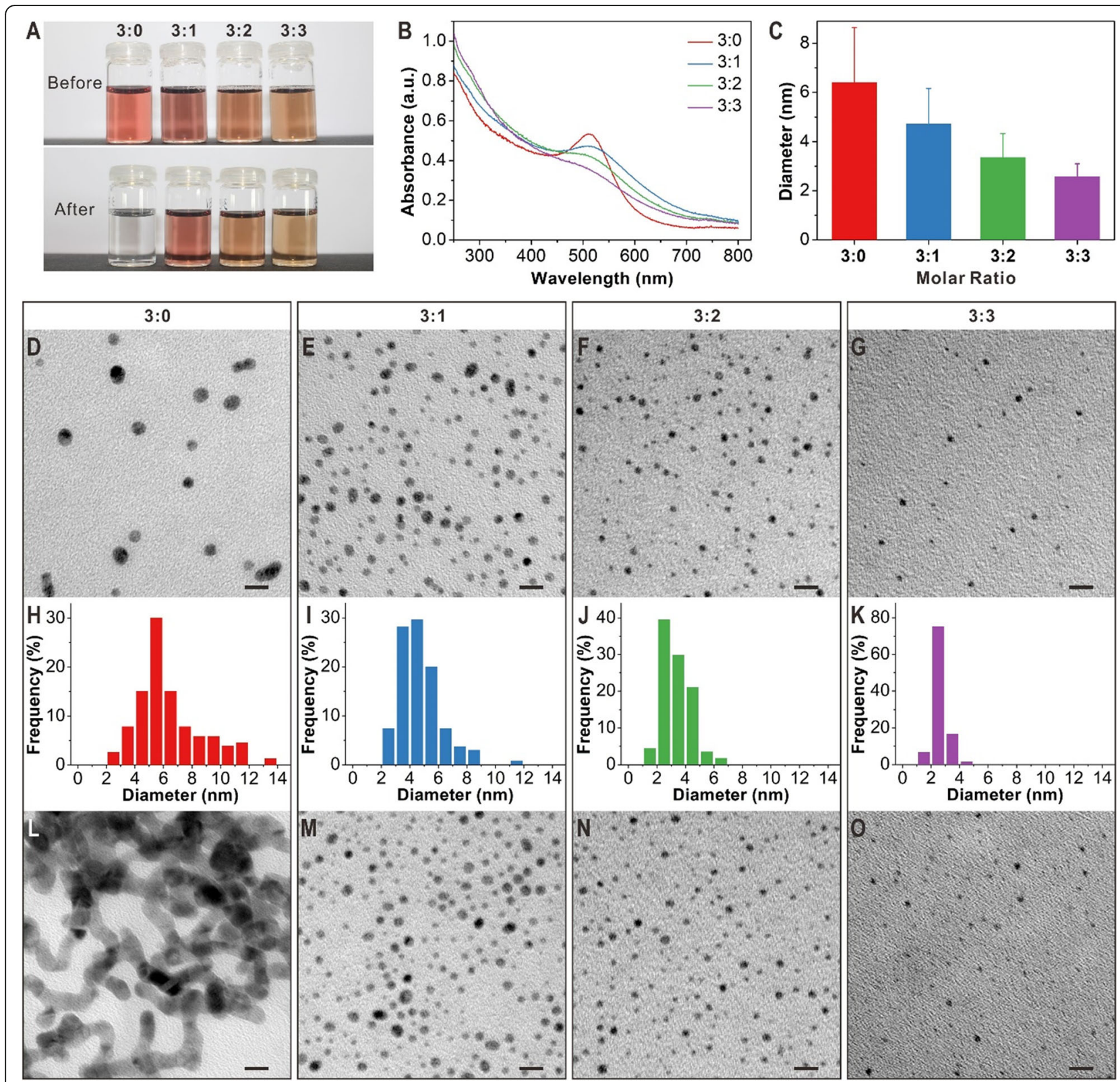

Fig. 2 Characterization of ultrasmall AuNPs prepared using $\mathrm{NaBH}_{4}$ as the reducing agent. a Optical images comparing solutions of AuNPs before and after purification by ultracentrifugation. The AuNPs were prepared using different molar ratios of chloroauric anions to amino groups from the denatured protein. $\mathbf{b}$ UV-vis spectra of the AuNPs before purification by ultracentrifugation. $\mathbf{c}$ The average size of AuNPs obtained by analyzing more than 100 particles from TEM images. (D-K) TEM images and size distributions of AuNPs prepared using different molar ratios of chloroauric anions to amino groups in the denatured protein before purification: $\mathbf{d}$ and $\mathbf{h}$ 3:0; $\mathbf{e}$ and $\mathbf{i} 3: 1 ; \mathbf{f}$ and $\mathbf{j} 3: 2 ; \mathbf{g}$ and $\mathbf{k}) 3: 3$. I-o TEM images of AuNPs after purification by ultracentrifugation: I 3:0; $\mathbf{m}$ 3:1; $\mathbf{n} 3: 2 ; \mathbf{0} 3: 3$. Scale bars: $10 \mathrm{~nm}$

Crucially, the samples prepared with denatured proteins demonstrated significantly enhanced stability compared to AuNPs prepared without the template $\left(\mathrm{HAuCl}_{4} /-\mathrm{NH}_{2}\right.$ molar ratio 3:0). After the formation of AuNPs, the reaction solutions were purified five times by centrifugation at a high speed of $5000 \mathrm{rpm}$. As shown in the bottom panel of Fig. 2a, colors of AuNPs prepared in the presence of the biopolymer template did not change even though they were repeatedly concentrated and recovered. The solutions stayed homogeneous and there was no obvious change for the UV spectra of these solutions (Figure S1). In contrast, the solution of the AuNPs prepared in the absence of the template changed to colorless after the purification step and black precipitates were observed at the bottom (see Figure S2). As displayed in the TEM image, severe aggregation occurred for the AuNPs without protection by denatured proteins (Fig. 2l). For AuNPs prepared in the presence 
of the biopolymer, all of them remained well-dispersed and no size change was observed (Fig. 2m-o). In addition, the AuNPs prepared by templated synthesis show excellent stability and dispersity even after storage at room temperature for one year (Figure S3). Therefore, the protein-derived biopolymer is indispensable for good water-solubility and excellent stability of AuNPs.

\subsection{AuNFs prepared using ascorbic acid as the reducing agent}

The choice of reducing agent has a great impact on the size and shape of AuNPs formed by templated synthesis. We further investigated the influence on particle morphology and size the when using L-ascorbic acid as the reducing agent and PEG-dcHSA as the template. By replacing $\mathrm{NaBH}_{4}$ with L-ascorbic acid, four $\mathrm{Au}$ nanostructures were synthesized with similar conditions as in Table 1. As shown in Fig. 3a, the reaction solutions showed different colors from red to purple and to blue when the amount of denatured proteins was increased. UV-vis spectra in Fig. 3b show characteristic peaks of gold nanoparticles and a red shift is observed when the molar ratio of chloroauric anions to amine groups in denatured protein was changed from 3:0 to 3:3. Both the colors and UV-vis spectra indicate an increase of particle size after adding more biopolymers. Furthermore, we used TEM to directly characterize the size and morphology of these Au nanostructures (Fig. 3c-k). Very interestingly, AuNFs with multiple extrusions were obtained, indicating a different particle formation mechanism when ascorbic acid was used as the reducing agent. More specifically, some very small gold dots were firstly formed, which served as seeds for the following reduction of $\mathrm{HAuCl}_{4}$. Because L-ascorbic acid is a mild reducing agent, the reactions were slower than those using $\mathrm{NaBH}_{4}$. Under slow reaction kinetics, gold atoms and small dots had enough time to diffuse and meet each other. Because the added biopolymer template may favor to bind certain crystalline phases [37], the nanoparticles thus grew along specific facets and formed branched morphologies. The diameter of AuNFs was tuned in 30 $\sim 70 \mathrm{~nm}$ by varying the amount of the denatured protein based on analysis of more than 100 nanoparticles in TEM images for each sample. The increase of biopolymer concentration leads to larger-sized AuNFs, which is a different trend in comparison to the synthesis of ultrasmall AuNPs using $\mathrm{NaBH}_{4}$ as the reducing agent. The reason for this interesting phenomenon is not clear. One possible reason is the larger area covered by the presence of more PEG-dcHSA. This facilitated the anisotropic growth of flower branches and the size increased. For the sample prepared in absence of the biopolymer template, spherical AuNPs with an average size of $35.4 \pm 10.0 \mathrm{~nm}$ were obtained. In addition, the TEM image in Fig. 3d even shows aggregation before purification for the sample prepared without the denatured protein template, indicating the poor stability of naked AuNPs. Surprisingly, all three AuNFs prepared in the presence of different amounts of denatured proteins demonstrated excellent stability despite their larger sizes compared to those ultrasmall AuNPs prepared using $\mathrm{NaBH}_{4}$ as the reducing agent (Fig. 3m-o and Figure S4).

\subsection{Catalytical reduction of $p$-nitrophenol by $\mathrm{Au}$ nanostructures}

Due to their high surface-to-volume ratios, gold nanomaterials are ideal catalysts for many organic reactions [8-10]. For example, the hydrogenation reaction of $p$-nitrophenol to $p$-aminophenol by $\mathrm{NaBH}_{4}$, which can be easily monitored by UV-vis spectroscopy, is a model reaction to evaluate the catalytic performance of noble metal catalysts [38]. Here, both ultrasmall AuNPs and AuNFs prepared under different conditions were used for the catalytical reduction of $p$-nitrophenol. As displayed in Fig. 4a-d, the characteristic peaks at $400 \mathrm{~nm}$ decreased for all spherical AuNPs prepared using $\mathrm{NaBH}_{4}$ as the reducing agent, indicating their catalytic activity for the hydrogenation reaction. More importantly, there is a clear trend that the reaction became faster when the AuNPs were prepared in the presence of more PEGdcHSA. The time to convert 90\% catalyzed by AuNPs prepared without the biopolymer template $\left(\mathrm{HAuCl}_{4} /\right.$ $-\mathrm{NH}_{2}$ molar ratio $=3: 0$ ) is more than $40 \mathrm{~min}$. In contrast, it took only 24 min for the AuNPs prepared with a $\mathrm{HAuCl}_{4} /-\mathrm{NH}_{2}$ molar ratio of 3:3 (Fig. 4e). By plotting $\ln \left(A_{o} / A_{t}\right)$ at $400 \mathrm{~nm}$ against the reaction time, the apparent rate constant $\left(k_{\text {app }}\right)$ is determined as the slope of fitted lines. As shown in Fig. 4f, the AuNPs prepared with a $\mathrm{HAuCl}_{4} /-\mathrm{NH}_{2}$ molar ratio of $3: 3$ show the highest $k_{\text {app }}$ of $1.673 \times 10^{-3} \mathrm{~s}^{-1}$. The apparent rate constants for AuNPs prepared with $\mathrm{HAuCl}_{4} /-\mathrm{NH}_{2}$ molar ratios of 3:0, $3: 1,3: 2$ are $9.273 \times 10^{-4} \mathrm{~s}^{-1}, 1.032 \times 10^{-3} \mathrm{~s}^{-1}, 1.488 \times$ $10^{-3} \mathrm{~s}^{-1}$, respectively. The higher catalytic activity of AuNPs synthesized with more templates is attributed to their smaller size and therefore higher surface-to-volume ratio to provide more catalytically active sites. Although the biopolymer coating may have a negative influence on the catalytic performance, it seems that the size effect is more significant. As the $\mathrm{Au}$ concentration $\left(C_{\mathrm{Au}}\right)$ in this catalytic reaction is only $0.163 \mathrm{mg} \mathrm{L}^{-1}$, the rate constant $\left(k_{\text {app }} / C_{\mathrm{Au}}\right)$ of the AuNPs prepared with a $\mathrm{HAuCl}_{4} /-\mathrm{NH}_{2}$ molar ratio of $3: 3$ is as high as $1.026 \times 10^{-2} \mathrm{~L} \mathrm{~s}^{-1} \mathrm{mg}^{-1}$.

UV-vis spectra showing the catalytic properties of AuNPs and AuNFs prepared with ascorbic acid for the hydrogenation of $p$-nitrophenol are depicted in Fig. 5ad. By plotting the conversion against the time, we can see that the reaction catalyzed by spherical AuNPs showed a relatively high speed (Fig. 5e). However, 


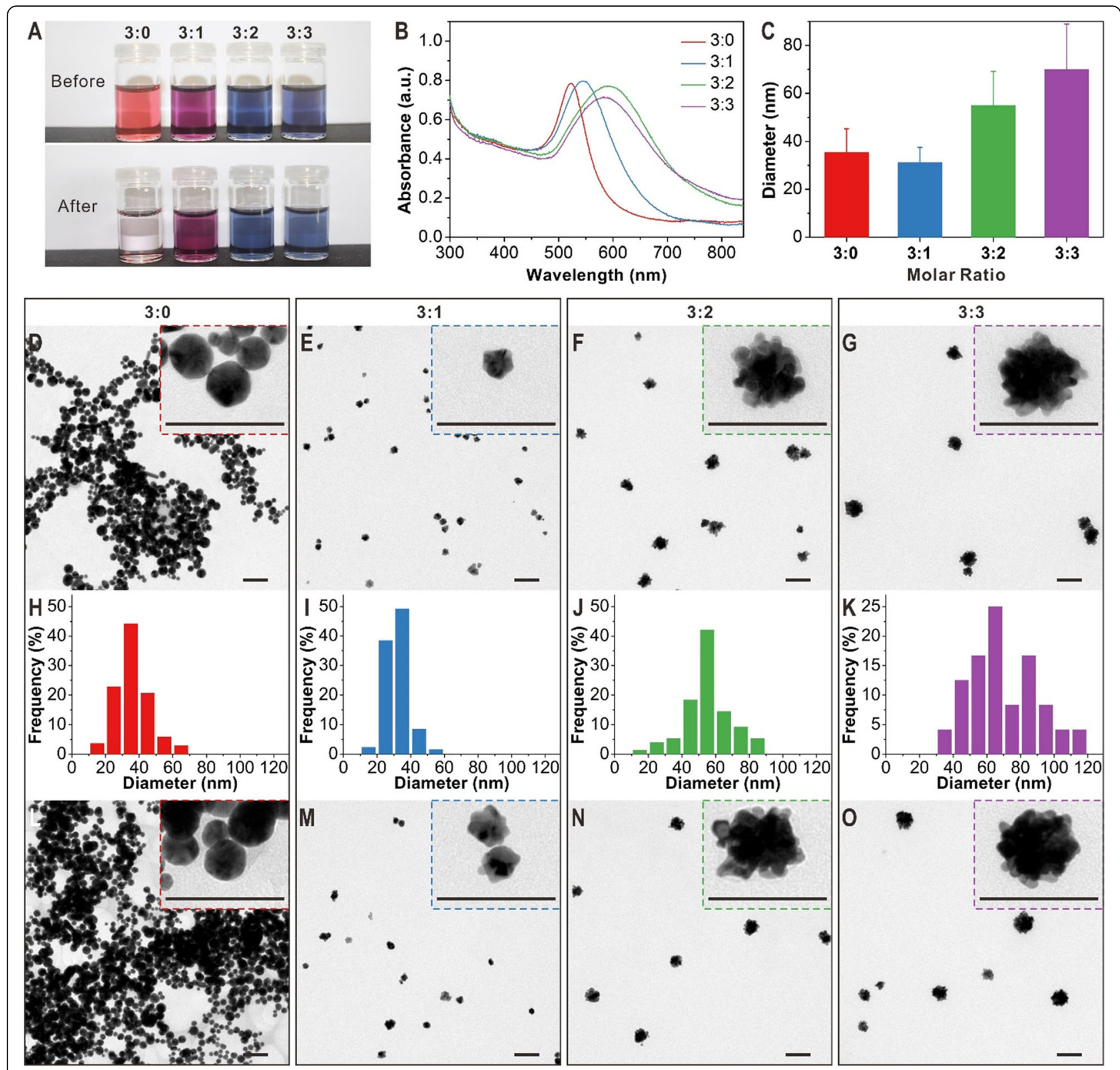

Fig. 3 Characterization of Au nanostructures prepared using L-ascorbic acid as the reducing agent. a Optical images comparing solutions of AuNPs and AuNFs before and after purification by ultracentrifugation. The gold nanostructures were prepared using different molar ratios of chloroauric anions to amine groups from the denatured protein. $\mathbf{b}$ UV-vis spectra of Au nanostructures before purification by ultracentrifugation. c The average size of Au nanostructures obtained by analyzing more than 100 particles from TEM images. $\mathbf{d}-\mathbf{k}$ TEM images and size distributions of Au nanostructures prepared using different molar ratios of chloroauric anions to amino groups of the denatured protein before purification: $\mathbf{d}$ and $\mathbf{h}$ 3:0; e and $\mathbf{i} 3: 1 ; \mathbf{f}$ and $\mathbf{j} 3: 2 ; \mathbf{g}$ and $\mathbf{k}$ 3:3. I-o TEM images of Au nanostructures after purification by ultracentrifugation: I 3:0; $\mathbf{m}$ 3:1; $\mathbf{n}$ 3:2; $\mathbf{o}$ 3:3. Scale bars: $100 \mathrm{~nm}$

AuNFs prepared in the presence of PEG-dcHSA demonstrate slower reaction kinetics especially in the beginning stages. This phenomenon probably is due to the biopolymer coating of AuNFs, which took some time for small molecules to diffuse. Fig. $5 \mathrm{f}$ shows the plot of $\ln \left(A_{o} / A_{t}\right)$ at $400 \mathrm{~nm}$ against the reaction time, the $k_{\text {app }}$ of spherical AuNPs $\left(\mathrm{HAuCl}_{4} /-\mathrm{NH}_{2}\right.$ molar ratios of 3:0) was determined as $1.518 \times 10^{-3} \mathrm{~s}^{-1}$. For AuNFs, we also calculated the $k_{\text {app }}$ for the period after diffusion. As the Au concentration $\left(C_{\mathrm{Au}}\right)$ here is $2.627 \mathrm{mg} \mathrm{L}^{-1}$, the rate constants $\left(k_{\text {app }} / C_{\mathrm{Au}}\right)$ catalyzed by AuNFs prepared with $\mathrm{HAuCl}_{4} /$ $-\mathrm{NH}_{2}$ molar ratios of 3:1, 3:2, 3:3 are $3.64 \times 10^{-4} \mathrm{~L} \mathrm{~s}^{-1}$ $\mathrm{mg}^{-1}, 4.21 \times 10^{-4} \mathrm{~L} \mathrm{~s}^{-1} \mathrm{mg}^{-1}$, and $4.69 \times 10^{-4} \mathrm{~L} \mathrm{~s}^{-1} \mathrm{mg}^{-1}$, respectively. Although the catalytic activity is not as high as ultrasmall AuNPs, they are still among the very effective Au catalysts in the literature [39-42]. 

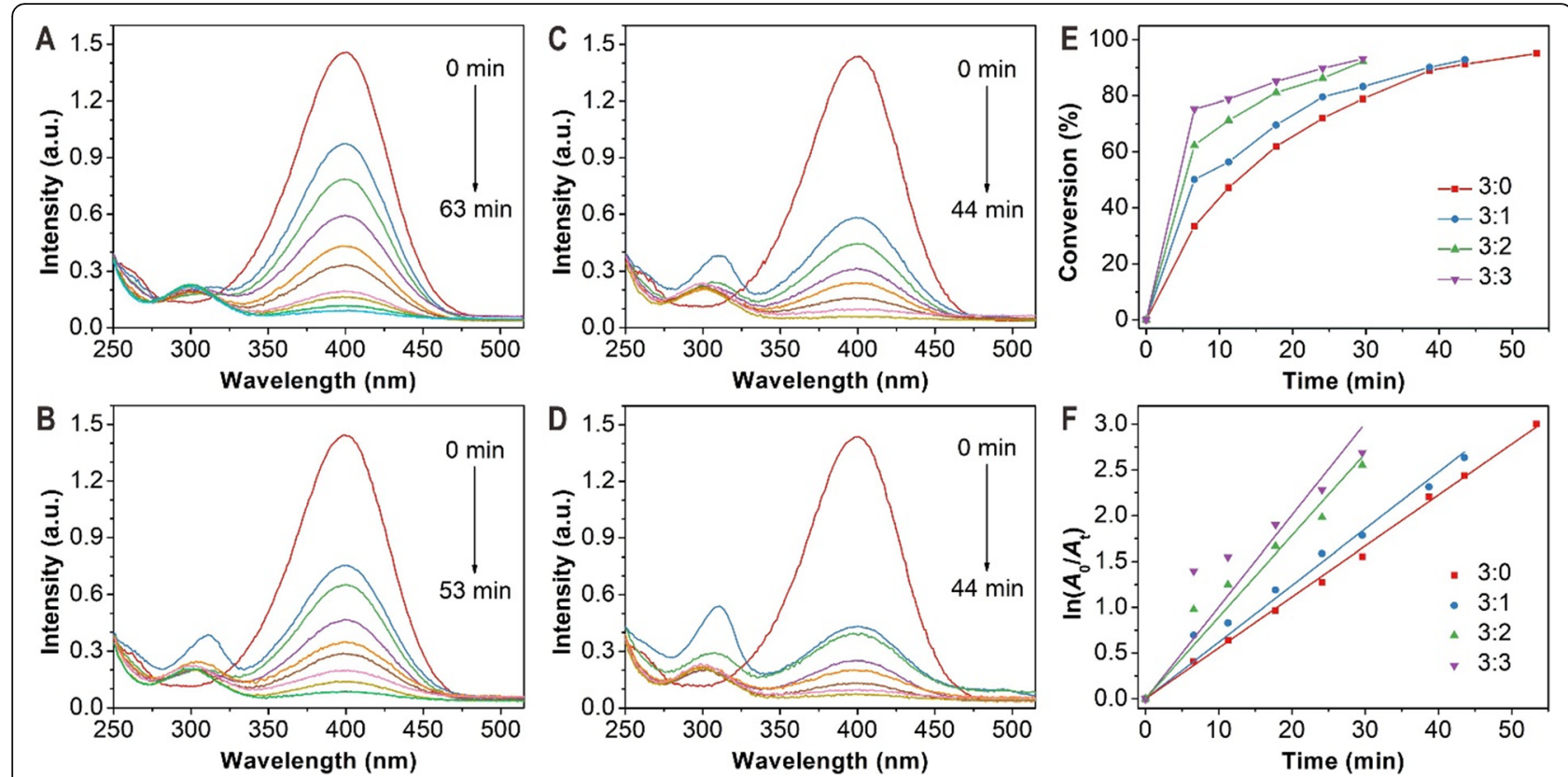

Fig. 4 Reduction of $p$-nitrophenol catalyzed by ultrasmall AuNPs prepared with $\mathrm{NaBH}_{4}$ using different molar ratios of chloroauric anions to amine groups on the denatured protein: a 3:0, b 3:1, c 3:2, d 3:3. e Conversion versus reaction time for the hydrogenation catalyzed by the ultrasmall AuNPs. f Plots of $\ln \left(A_{0} / A_{t}\right)$ at $400 \mathrm{~nm}$ versus reaction time for the hydrogenation catalyzed by the ultrasmall AuNPs

3.5 Synthesis of PtNPs and their catalytic performance In addition to well-defined AuNPs and AuNFs, other noble metal nanoparticles can also be prepared using the protein-derived biopolymer as template. For example, PtNPs have also attracted broad attention in catalysis and nanomedicine [43-46]. We further explored the preparation of PtNPs in the presence of PEG-dcHSA by reducing $\mathrm{H}_{2} \mathrm{PtCl}_{6}$ with $\mathrm{NaBH}_{4}$. The molar ratio of $\mathrm{PtCl}_{6}{ }^{2-}$ anions to amine groups of PEG-dcHSA in the solution was set as 3:2. As shown in Fig. 6a, water-soluble PtNPs
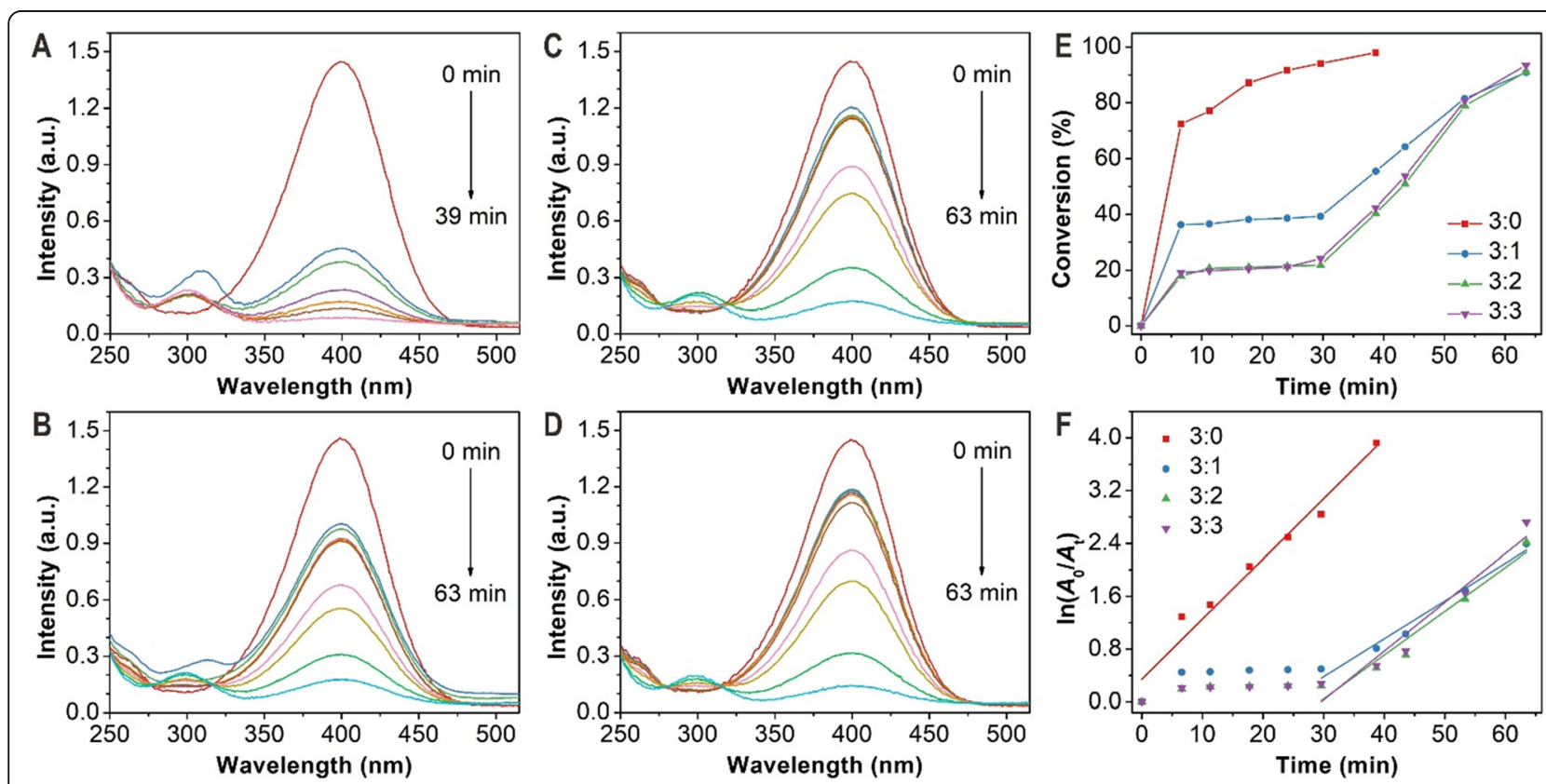

Fig. 5 Reduction of $p$-nitrophenol catalyzed by gold nanostructures prepared with L-ascorbic acid using different molar ratios of chloroauric anions to amine groups on the denatured protein: a 3:0, b 3:1, c 3:2, d 3:3. e Conversion versus reaction time for the hydrogenation catalyzed by these Au nanostructures. $\mathbf{f} \ln \left(A_{0} / A_{t}\right)$ at $400 \mathrm{~nm}$ versus reaction time for the hydrogenation catalyzed by these Au nanostructures 

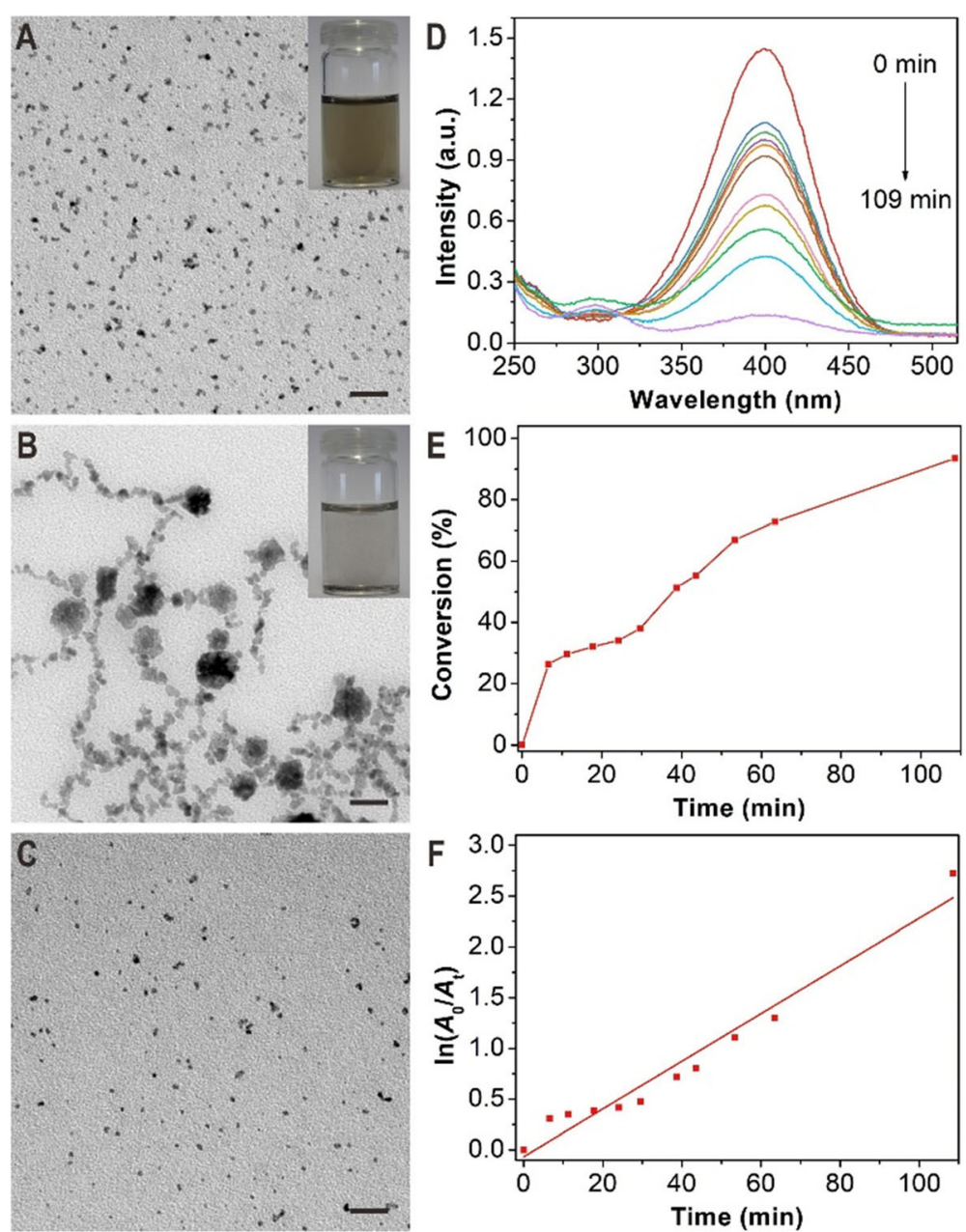

Fig. 6 a TEM image of PtNPs prepared using a molar ratio of $\mathrm{PtCl}_{6}{ }^{2-}$ anions to amine groups of PEG-dcHSA of 3:2. $\mathbf{b}$ TEM image of Pt aggregates prepared in the absence of the template. c TEM image of PdNPs after purification by ultracentrifugation. $\mathbf{d}$ Reduction of $p$-nitrophenol catalyzed by PtNPs. e Conversion versus reaction time for the hydrogenation catalyzed by PtNPs. $\mathbf{f}$ Plot of $\ln \left(A_{0} / A_{t}\right)$ at $400 \mathrm{~nm}$ versus reaction time for the hydrogenation catalyzed by these PtNPs. Scale bars: $20 \mathrm{~nm}$

with good dispersity and an average size of $\sim 3 \mathrm{~nm}$ were obtained. In a control experiment, very severe aggregation was observed for PtNPs prepared without adding the denatured protein (Fig. 6b). In addition, the size and dispersity of PtNPs by templated synthesis did not change even after purification several times by ultracentrifugation at a high speed of $5000 \mathrm{rpm}$, indicating their excellent stability (Fig. 6c).

We further evaluated the catalytic performance of PtNPs using the same hydrogenation reaction. As shown in Fig. 6d, the characteristic peak at $400 \mathrm{~nm}$ of $p$-nitrophenol gradually decreased in two hours. The conversion reaches $90 \%$ after reacting for $100 \mathrm{~min}$ (Fig. 6e). By plotting $\ln \left(A_{o} / A_{t}\right)$ at $400 \mathrm{~nm}$ against the reaction time, the $k_{\text {app }}$ was obtained as $3.913 \times 10^{-4} \mathrm{~s}^{-1}$ (Fig. 6f). Therefore, PtNPs synthesized and stabilized with PEGdcHSA can also serve as an effective catalyst for the hydrogenation reaction. In comparison, a catalytic study for PtNPs prepared without the biopolymer template was not possible because the particles were difficult to purify and the amount could not be determined.

\section{Conclusion}

In summary, denatured proteins have been reported as a novel template for the synthesis of water-soluble, ultrastable, and well-defined noble metal nanoparticles (AuNPs, AuNFs, PtNPs). Au nanostructures of different shapes (spherical and flower-like) have been prepared using $\mathrm{NaBH}_{4}$ or ascorbic acid as the reducing agent. The sizes of Au nanostructures have been controlled by tuning the molar ratio of metal ions to amino groups of the template. Compared to nanoparticles prepared without the template, these metal nanoparticles prepared by templated synthesis demonstrated much better stability even after high speed centrifugation or storage at room temperature for one year. Moreover, these nanoparticles 
have been used as efficient catalysts for the hydrogenation of $p$-nitrophenol to $p$-aminophenol. AuNPs with an average size of $2 \mathrm{~nm}$ show the highest catalytic efficiency with a rate constant of $1.026 \times 10^{-2} \mathrm{~L} \mathrm{~s}^{-1} \mathrm{mg}^{-1}$. These metal nanoparticles with tunable size and shape, as well as good stability, dispersity and water-solubility may find great potentials in catalysis, sensors, biomedicine and many other fields.

\section{Supplementary information}

Supplementary information accompanies this paper at https://doi.org/10 1186/s42825-020-00020-5.

Additional file 1: Figure S1. UV-vis spectra of ultrasmall AuNPs after purification by ultracentrifugation. Figure S2. Enlarged photo of AuNPs prepared in the absence of the biopolymer template after purification five times by ultracentrifugation. Figure S3. Digital photo (A) and TEM images (B-D) showing the excellent stability and dispersity of AuNPs after storage for one year at room temperature. Figure S4. Digital photo (A) and TEM images (B-D) showing the excellent stability and dispersity of AuNFs after storage for one year at room temperature.

\begin{abstract}
Abbreviations
AuNFs: Gold nanoflowers; AuNPs: Gold nanoparticles; CHSA: Cationic HSA; EDC.HCl: N-(3-Dimethylaminopropyl)-N'-ethylcarbodiimide hydrochloride; EDTA: Ethylenediaminetetraacetic acid; $\mathrm{HAuCl}_{4} \cdot 3 \mathrm{H}_{2} \mathrm{O}$ : Gold (III) chloride trihydrate; $\mathrm{H}_{2} \mathrm{PtCl}_{6} \cdot \mathrm{xH}_{2} \mathrm{O}$ : Hydrogen hexachloroplatinate (IV) hydrate; HSA: Human serum albumin; $k_{a p p}$ : Apparent rate constant; MALDIToF: Matrix-assisted laser desorption/ionization time-of-flight; $\mathrm{Ml-NH_{2 }}$ : N-(2aminoethyl) maleimide trifluoroacetate salt; $\mathrm{NaBH}_{4}$ : Sodium borohydride; NHS-PEG: O-[(N-succinimidyl)succinyl-aminoethyl]-O'-methylpolyethylene glycol; PEG: Polyethylene glycol; PEG-cHSA: PEGylated CHSA; PEGdCHSA: Denatured PEG-CHSA; PtNPs: Platinum nanoparticles; TCEP: Tris(2carboxyethyl) phosphine hydrochloride; TEM: Transmission electron microscopy
\end{abstract}

\section{Acknowledgements}

The authors thank Julius Gemen for his assist with part of the experiments. Christopher Synatschke and Nicole Kirsch-Pietz are gratefully acknowledged for critically reading the manuscript.

\section{Authors' contributions}

C.C. performed the experiments and wrote the manuscript. D.Y.W.N. and T.W supervised the project and revised the manuscript. All authors discussed the results and commented on the manuscript. The author(s) read and approved the final manuscript.

\section{Funding}

The authors acknowledge financial support by the Deutsche Forschungsgemeinschaft (DFG, German Research Foundation) - Project number 213555243 SFB 1066 (A06). C.C. is grateful for a doctoral fellowship from Promotionskolleg Pharmaceutical Biotechnology of UIm University funded by the state of Baden-Württemberg.

\section{Availability of data and materials}

All data generated or analyzed during this study are included in this published article and its supplementary information.

\section{Competing interests}

The authors declare that they have no competing interests.

\section{Author details}

${ }^{1}$ Max Planck Institute for Polymer Research, Ackermannweg 10, 55128 Mainz, Germany. ${ }^{2}$ Ulm University, Albert-Einstein-Allee 11, 89081 Ulm, Germany.
Received: 9 January 2020 Accepted: 18 March 2020

Published online: 23 March 2020

\section{References}

1. Eustis S, El-Sayed MA. Why gold nanoparticles are more precious than pretty gold: Noble metal surface plasmon resonance and its enhancement of the radiative and nonradiative properties of nanocrystals of different shapes. Chem Soc Rev. 2006;35:209.

2. Sau TK, Rogach AL. Nonspherical Noble metal nanoparticles: colloidchemical synthesis and morphology control. Adv Mater. 2010;22:1781.

3. Zhou W, Gao X, Liu DB, Chen XY. Gold nanoparticles for in vitro diagnostics. Chem Rev. 2015;115:10575

4. Sau TK, Rogach AL, Jackel F, Klar TA, Feldmann J. Properties and applications of colloidal nonspherical Noble metal nanoparticles. Adv Mater. 2010;22:1805.

5. Arvizo RR, Bhattacharyya S, Kudgus RA, Giri K, Bhattacharya R, Mukherjee P. Intrinsic therapeutic applications of noble metal nanoparticles: past, present and future. Chem Soc Rev. 2012;41:2943.

6. Zeng J, Huang JL, Lu W, Wang XP, Wang B, Zhang SY, Hou JG. Necklace-like noble-metal hollow nanoparticle chains: synthesis and tunable optical properties. Adv Mater. 2007;19:2172.

7. Bigall NC, Reitzig M, Naumann W, Simon P, van Pee KH, Eychmuller A. Fungal templates for noble-metal nanoparticles and their application in catalysis. Angew Chem Int Ed. 2008;47:7876.

8. Corma A, Garcia H. Supported gold nanoparticles as catalysts for organic reactions. Chem Soc Rev. 2008:37:2096.

9. Ide MS, Davis RJ. The important role of hydroxyl on oxidation catalysis by gold nanoparticles. Acc Chem Res. 2014;47:825.

10. Mitsudome T, Kaneda K. Gold nanoparticle catalysts for selective hydrogenations. Green Chem. 2013;15:2636.

11. Shimmin RG, Schoch AB, Braun PV. Polymer size and concentration effects on the size of gold nanoparticles capped by polymeric thiols. Langmuir. 2004;20:5613.

12. Oh E, Susumu K, Goswami R, Mattoussi H. One-phase synthesis of watersoluble gold nanoparticles with control over size and surface functionalities. Langmuir. 2010;26:7604.

13. Enciso AE, Doni G, Nifosi R, Palazzesi F, Gonzalez R, Ellsworth AA, Coffer JL, Walker AV, Pavan GM, Mohamed AA, Simanek EE. Facile synthesis of stable, water soluble, dendron-coated gold nanoparticles. Nanoscale. 2017;9:3128.

14. Salorinne K, Man RWY, Li CH, Taki M, Nambo M, Crudden CM. Water-soluble Nheterocyclic Carbene-protected gold nanoparticles: size-controlled synthesis, stability, and optical properties. Angew Chem Int Ed. 2017;56:6198.

15. Yang WT, Guo WS, Chang J, Zhang BB. Protein/peptide-templated biomimetic synthesis of inorganic nanoparticles for biomedical applications. J Mater Chem B. 2017;5:401.

16. Chakraborty I, Parak WJ. Protein-induced shape control of Noble metal nanoparticles. Adv Mater Interfaces. 2019;6:1801407.

17. Dickerson MB, Sandhage KH, Naik RR. Protein- and peptide-directed syntheses of inorganic materials. Chem Rev. 2008;108:4935.

18. Li Y, Tang ZH, Prasad PN, Knecht MR, Swihart MT. Peptide-mediated synthesis of gold nanoparticles: effects of peptide sequence and nature of binding on physicochemical properties. Nanoscale. 2014;6:3165.

19. Virkutyte J, Varma RS. Green synthesis of metal nanoparticles: biodegradable polymers and enzymes in stabilization and surface functionalization. Chem Sci. 2011;2:837.

20. Liu GY, Luo QQ, Wang HB, Zhuang WH, Wang YB. In situ synthesis of multidentate PEGylated chitosan modified gold nanoparticles with good stability and biocompatibility. RSC Adv. 2015;5:70109.

21. Sun LJ, Li J, Cai J, Zhong L, Ren GH, Ma QM. One pot synthesis of gold nanoparticles using chitosan with varying degree of deacetylation and molecular weight. Carbohydr Polym. 2017;178:105.

22. Yen HJ, Young YA, Tsai TN, Cheng KM, Chen XA, Chen YC, Chen CC, Young $J$ J, Hong PD. Positively charged gold nanoparticles capped with folate quaternary chitosan: synthesis, cytotoxicity, and uptake by cancer cells. Carbohydr Polym. 2018;183:140.

23. Zhang KT, Shen MG, Liu H, Shang SB, Wang D, Liimatainen H. Facile synthesis of palladium and gold nanoparticles by using dialdehyde nanocellulose as template and reducing agent. Carbohydr Polym. 2018;186:132.

24. Lu LH, Ai K, Ozaki Y. Environmentally friendly synthesis of highly monodisperse biocompatible gold nanoparticles with urchin-like shape. Langmuir. 2008;24:1058. 
25. Goswami N, Saha R, Pal SK. Protein-assisted synthesis route of metal nanoparticles: exploration of key chemistry of the biomolecule. J Nanopart Res. 2011;13:5485.

26. Leng YM, Fu L, Ye LQ, Li B, Xu XM, Xing XJ, He JB, Song YL, Leng CL, Guo YM, Ji XX, Lu ZW. Protein-directed synthesis of highly monodispersed, spherical gold nanoparticles and their applications in multidimensional sensing. Sci Rep. 2016;6:28900.

27. Wei G, Wang L, Sun LL, Song YH, Sun YJ, Guo CL, Yang T, Li ZA. Type I collagen-mediated synthesis and assembly of UV-photoreduced gold nanoparticles and their application in surface-enhanced Raman scattering. J Phys Chem C. 2007;111:1976.

28. Wu YZ, Chakrabortty S, Gropeanu RA, Wilhelmi J, Xu Y, Er KS, Kuan SL, Koynov K, Chan Y, Weil T. pH-responsive quantum dots via an albumin polymer surface coating. J Am Chem Soc. 2010;132:5012.

29. Wu YZ, Pramanik G, Eisele K, Weil T. Convenient approach to polypeptide copolymers derived from native proteins. Biomacromolecules. 2012;13:1890.

30. Chen CJ, Wunderlich K, Mukherji D, Koynov K, Heck AJ, Raabe M, Barz M, Fytas G, Kremer K, Ng DYW, Weil T. Precision anisotropic brush polymers by sequence controlled chemistry. J Am Chem Soc. 2020;142:1332.

31. Wu YZ, Eisele K, Doroshenko M, Algara-Siller G, Kaiser U, Koynov K, Weil T. A quantum dot Photoswitch for DNA detection, gene transfection, and livecell imaging. Small. 2012;8:3465.

32. Wu YZ, Ermakova A, Liu WN, Pramanik G, Vu TM, Kurz A, McGuinness L, Naydenov B, Hafner S, Reuter R, Wrachtrup J, Isoya J, Fortsch C, Barth H, Simmet T, Jelezko F, Weil T. Programmable biopolymers for advancing biomedical applications of fluorescent Nanodiamonds. Adv Funct Mater. 2015;25:6576.

33. Chen CJ, Ng DYW, Weil T. Polymer-grafted gold nanoflowers with temperature-controlled catalytic features by in situ particle growth and polymerization. Mater Chem Front. 2019;3:1449.

34. Wu YZ, Ihme S, Feuring-Buske M, Kuan SL, Eisele K, Lamla M, Wang YR, Buske C, Weil T. A Core-Shell albumin copolymer Nanotransporter for high capacity loading and two-step release of doxorubicin with enhanced antileukemia activity. Adv Healthc Mater. 2013;2:884

35. Haiss W, Thanh NTK, Aveyard J, Fernig DG. Determination of size and concentration of gold nanoparticles from UV-Vis spectra. Anal Chem. 2007;79:4215.

36. ten Hove JB, Schijven LMI, Wang JY, Velders AH. Size-controlled and watersoluble gold nanoparticles using UV-induced ligand exchange and phase transfer. Chem Commun. 2018;54:13355.

37. Xia YN, Xiong YJ, Lim B, Skrabalak SE. Shape-controlled synthesis of metal Nanocrystals: simple chemistry meets complex physics? Angew Chem Int Ed. 2009;48:60.

38. Zhao PX, Feng XW, Huang DS, Yang GY, Astruc D. Basic concepts and recent advances in nitrophenol reduction by gold- and other transition metal nanoparticles. Coord Chem Rev. 2015;287:114

39. Marcelo G, Lopez-Gonzalez M, Mendicuti F, Tarazona MP, Valiente M. Poly(N-isopropylacrylamide)/gold hybrid hydrogels prepared by catechol redox chemistry. Characterization and Smart Tunable Catalytic Activity. Macromolecules. 2014;47:6028.

40. Rashid MH, Bhattacharjee RR, Kotal A, Mandal TK. Synthesis of spongy gold nanocrystals with pronounced catalytic activities. Langmuir. 2006:22:7141.

41. Wang ML, Jiang TT, Lu Y, Liu HJ, Chen Y. Gold nanoparticles immobilized in hyperbranched polyethylenimine modified polyacrylonitrile fiber as highly efficient and recyclable heterogeneous catalysts for the reduction of 4nitrophenol. J Mater Chem A. 2013;1:5923.

42. Ye YL, Jin M, Wan DC. One-pot synthesis of porous monolith-supported gold nanoparticles as an effective recyclable catalyst. J Mater Chem A. 2015;3:13519.

43. Cheong SS, Watt JD, Tilley RD. Shape control of platinum and palladium nanoparticles for catalysis. Nanoscale. 2010;2:2045.

44. Lara P, Philippot K. The hydrogenation of nitroarenes mediated by platinum nanoparticles: an overview. Catal Sci Technol. 2014;4:2445.

45. Pedone D, Moglianetti M, De Luca E, Bardi G, Pompa PP. Platinum nanoparticles in nanobiomedicine. Chem Soc Rev. 2017;46:4951.

46. Peng ZM, Yang $H$. Designer platinum nanoparticles: control of shape, composition in alloy, nanostructure and electrocatalytic property. Nano Today. 2009;4:143.

\section{Publisher's Note}

Springer Nature remains neutral with regard to jurisdictional claims in published maps and institutional affiliations.

\section{Submit your manuscript to a SpringerOpen ${ }^{\odot}$ journal and benefit from:}

- Convenient online submission

- Rigorous peer review

- Open access: articles freely available online

- High visibility within the field

- Retaining the copyright to your article

Submit your next manuscript at $\boldsymbol{\nabla}$ springeropen.com 